\title{
The evolution of gender-inclusive language. Evidence from the German Bundestag, 1949-2021
}

\author{
Christian Stecker (Technical University of Darmstadt) \\ Jochen Müller (Humboldt-Universität zu Berlin) \\ Andreas Blätte (University of Duisburg-Essen) \\ Christoph Leonhardt (University of Duisburg-Essen)
}

Working Paper, 13.07.2021

\begin{abstract}
Gender-inclusive language is an important issue in the struggle for political equality between women and men. Parliaments are an important site in this struggle as they both reflect and shape gender-relations in society. Based on a novel high-quality corpus of all its debates we study the evolution of gender-fair language in the German parliament, Bundestag, between 1949 and 2021. As a "gender language" with a grammatical gender, German offers ideal conditions to inspect semantically symmetric male and female forms of personal nouns. Our analysis of more than 2.5 million occurrences of 1,600 lemmas of personal nouns reveals that female forms had been virtually non-existent in debates before experiencing a dramatic increase since the 1980s. This evolution in language use has been induced by the gender, partisan affiliation and generational affiliation of MPs.
\end{abstract}

\section{Keywords}

gender-inclusive language, legislative debate, German Bundestag

\section{Acknowledgements}

We thank Anusha Fraikin, Elias Koch, Daniel Kuhlen, Tim Rieth, and Lena Wolff for valuable research assistance. 


\section{Introduction}

Language is central to the construction and communication of gender and the discursive negotiation of power relations between the sexes. According to the feminist critique of language starting in the 1970s (Lakoff 1973), the use of language is tilted towards "male as norm." The dominance of male generics, so the criticism goes, contributes to an androcentric world-view, marginalizes women and proliferates gender stereotypes. As language is not only a reflection of reality but also shapes reality itself (Boroditsky 2009), language use is an important object for those who want to curb political and societal gender inequalities (Cameron 2003). Many formal and informal efforts of language planning and reform mark the struggle for gender-fair language.

Parliaments are a central site in this struggle. How Members of Parliament (MPs) acknowledge men and women in their talk influences to what extent parliaments are gender-just beyond their formally gender-neutral rules (Lowndes 2020). The degree of gender-fairness in the communicative business of the people's house may also embody the broader state of gender equality in a society and reflect the divisiveness of the issue. Language use in legislatures is also a correlate of the discursive awareness for women's interest and responsiveness in substantive decisions (Lovenduski 2005; Phillips 2003: 98). Finally, as a prominent convention of political elites, parliaments can also be a driver of gender-fair language among the citizenry.

Against this background, we study the evolution of gender-fair language in the German Bundestag from 1949 to 2021. With our novel high-quality corpus of all speeches ever given in the Bundestag (Blätte 2020a) we explore the role of various factors including party-political and compositional ("critical mass" of women) features, individual characteristics of MPs (gender) and politico-sociological processes (e. g. generational renewal). Our results highlight the role of left and green-alternative parties in changing language use. Moreover, female MPs - regardless of their political affiliation - more often use gender-fair language than their male colleagues.

Our analysis combines political, sociological, linguistic and historic perspectives on language use among the political elite. It provides novel insights into a political conflict that forms an important part of newly emerged value-based cleavages in democracies (Kriesi 2010). Our analysis hopefully encourages further research into the political struggle for gender-fair communication in other languages, parliaments and political texts.

\section{The political struggle for gender equality and gender-fair language}

How gender is and can be linguistically represented depends on the structural properties of individual languages (Gygax et al. 2019). Languages differ as to how they represent sex or gender of personal nouns that may refer to occupations (e. g. surgeon), political or social groups (e. g. citizens) or nationalities (e. g. Germans). An important distinction runs between gender languages, natural gender languages, and genderless languages (Hellinger and Bussmann 2003: 2; Stahlberg et al. 2007). In a gender language personal nouns correspond to a gender category entailing feminine, masculine, and often also neuter forms. Arabic, Dutch, French or German are examples for gender languages. In natural gender languages, such as English, a grammatical gender of personal nouns is rare and most personal nouns can in principle refer to both men and women. There, gender is expressed by personal pronouns that agree with the noun, like she or he. In genderless languages (e. g. Finnish) neither personal nouns nor pronouns are marked for gender.

It has been suggested, that already this structural feature of (non)-existing grammatical gender in a language influences hard indicators of gender equality (Prewitt-Freilino, Caswell, and Laakso 2012). Yet, in principle, all languages could be used in a gender-fair way by consistently using male and female referents or sex-marked pronouns, or by symmetrically ignoring gender altogether (Stahlberg et al. 2007: 167). In reality, however, the unequal treatment of women and men is a ubiquitous feature of language.

Various psycho-linguistic studies have established, that the widespread use of gender-biased language has a significant impact on people's attitudes and behaviors. The default use of male pronouns for high-status jobs (e. g. "The surgeon [...]. He [...]"), for example, and the lexical marking of marital status for women but not for men (such as in the English "Miss") determine self-conceptions and aspirations of women and men and the mental representations of social hierarchies between the sexes (Hellinger, Bussmann, and Motschenbacher 
2015; Reynolds, Garnham, and Oakhill 2006). The political project of achieving equality between men and women has, hence, not only focused on the descriptive and substantive representation of women in parliaments and policy decisions (Mansbridge 1999; Wängnerud 2009). It has always also been a struggle about the visibility of women in everyday language (Cameron 2012). Two politico-linguistic strategies are particularly important in treating women and men equally: Neutralization, that is using gender-unmarked nouns, and feminization, that is replacing or supplementing male generics with female referents (Sczesny, Formanowicz, and Moser 2016).

\section{What drives gender inclusive language?}

Parliaments are a central arena in the political struggle for gender equality. On the one hand, the sufficient descriptive representation of women in parliaments is core to gender equality. After decades of gross underrepresentation the number of female MPs has risen in many modern democracies, partly aided by gender quotas regulating the pathways to power (Eder, Fortin-Rittberger, and Kroeber 2016; Norris 2004: 194). Moreover, legislative activities such as debates (Bäck and Debus 2018), parliamentary questions (Bird 2005), and legislative decision (Bratton and Ray 2002; Celis 2006) determine to what extent women's substantive political interests acquire sufficient recognition.

On the other hand, parliaments are also arenas of elite communication. How the elite speaks of women (or ignores them) embodies their attitudes and awareness of women's issues and may well be itself a correlate of the substantive representation of women's interests. Gender-biased language in parliament is likely conducive to representational biases at the detriment of women. Moreover, elite talk will be heard by large shares of the population (Tresch 2008). How women are mentioned and talked about in the "house of the people" will partly diffuse into society and will also influence how well women feel represented.

What influences the use of gender-fair (or unfair) language in parliaments? To begin with, curbing the discrimination of woman and other political minorities via the reform of language use and institutions (Young 2010) has been an important part of the broader progressive agenda among extra-parliamentary activists and green-alternative parties that entered the political stage in the 1960s and 1970. In our case, Germany, feminist voices had been strong within the student's movement of the 1960s and its organizational expression in the party system, the Greens. With the Greens entering the Bundestag for the very first time in 1983, not only did the share of women MPs increase, "male as norm" in political representation - and speech also became contested. Hence, MPs from green-alternative and left parties are likely to be early-adopters of gender fair language.

Beyond the affiliation with parties and their ideologies various individual-level factors may further account for the use of gender-fair language. The gender of the speaker itself is an obvious factor. Various studies have identified gendered effect on legislative behavior such as committee membership (Thomas 1994), parliamentary questions or debate participation (e.g. Bäck and Debus 2018). Studies also identified gendered communication styles (Blankenship and Robson 1995; Dietrich, Hayes, and O'Brien 2019; Kinsky, Sältzer, and Walter 2021). Women have been found to talk in a less adversarial way or to refer more often to personal experiences and specific policy effects on clearly circumscribed groups. Men, however, take more abstract perspectives (Hargrave and Langengen 2020: 7). Such a male perspective may correspond with the tendency to use the more abstract generic masculine forms, while the sensitivity of women for specific groups will also invite the use of feminine forms. Moreover, women directly experience and are directly affected by linguistic marginalization in everyday language and will likely form an intrinsic interest for gender-fair language.

A better descriptive representation of women in parliaments would, hence, directly improve the genderinclusiveness of language. If women speak more gender-inclusive than men, then every additional woman will change the average debate. Yet, also more indirect effects are conceivable. Along the lines of "critical mass"-theory an increasing number of women in parliaments could not only change parliamentary practice and outputs but also the behavior of their male colleagues and their awareness for women's issues (Wängnerud 2009: 65). One the one hand, it can be - consciously and subconsciously - "contagious" for men if women in parliaments use more gender-fair language. On the other hand, the sheer (increasing) presence of women in 
legislatures as fellow committee members, as (female) minister or as Bundeskanzlerin influences the mental processes and language behavior of male politicians . More generally, language use in parliament will both reflect the status quo of sex roles (e. g. the overall share of female professors or ministers) as well as the attitudes of individual MPs.

Generational effects are also likely drivers of language evoluation. The strive for gender equality has been linked to deep structural transformations of societies and their economies that created generational differences in attitudes towards sex roles. While these differences may vary in magnitude across time, their existence will likely be a ubiquitous feature. In analogy to the findings of Inglehart and Norris (2005: 19), younger MPs, women in particular, may express their adherence to egalitarian values by using gender-inclusive language, while older MPs are likely to use more traditional language patterns.

\section{Research Design and Data}

We study the evolution of gender-inclusive language using a novel high-quality corpus of the German Bundestag (Blätte 2020a) containing all debates and speeches ever given since it convened for the first time in September 1949. Legislative debates have proven to be a valuable source for studying institutional effects (Proksch and Slapin 2012), party interaction (Valentim and Widmann 2021) and intra-party dynamics (Bäck, Debus, and Fernandes 2021; Blätte, Müller, and Stecker 2021). To our knowledge our study is the first to take advantage of legislative debates to explore long-term politico-linguistic developments.

Our corpus of the Bundestag contains more than 266 million tokens. Unfortunately, earlier plenary protocols of the Bundestag are only available as weakly structured text images separated into two columns and running headers and footers. Parsing more than 4229 plenary protocols into analyzable text has been a long-term endeavor requiring high computational sophistication as well as intense grappling with the text. To our knowledge GermaParl is currently the only corpus of all speeches given in the Bundestag with complete and precise annotations of speakers and parties. We reduce the corpus to speeches given by MPs and members of the government, speeches by guests or members of the second chamber (Bundesrat) are excluded. We also exclude interjections. The data is merged with information on the individual speakers and the respective party groups. Most importantly, data on MP's gender and day of birth is added using the Comparative Legislator Database and the respective R-package legislatoR (Goebel and Munzert 2020). ${ }^{1}$ The bulk of data-wrangling and analysis were conducted with the invaluable help of the tidyverse (Wickham et al. 2019) and the polmineR-package (Blätte 2020b).

The German language offers very fruitful structural conditions to study the use of gender-inclusive language. Most importantly, it is a gender language exhibiting a grammatical gender (Stahlberg et al. 2007). Moreover, it uses a powerful technique for forming feminine words from (generic) masculine forms. By adding the suffix "-in" to singular forms and "-innen" to plural forms almost all male personal nouns can be feminized (Bußmann and Hellinger 2003: 153), e. g.: politician(s) = Politiker/-in(nen). This structural feature enables us to study semantically symmetric pairs of male and female forms in a bag-of-words approach. To the contrary, the English language poses considerable obstacles for studying gender-specificity (but see Twenge, Campbell, and Gentile 2012). There is no grammatical gender and although some feminine derivations exist, these are often considered semantically asymmetrical (e. g. steward/-ess) if not derogative (e. g. govern/-ess) (Hellinger 2001: 109). Finding gender markings would require a focus on personal pronouns, which will not always accompany a personal noun or necessitate the demanding identification of syntactic relations (Kinsky, Sältzer, and Walter 2021).

To assess gender-fair language in the German Bundestag we constructed a dictionary containing all personal nouns ever uttered in the plenary. More specifically, we created symmetric pairs of singular and plural feminine and masculine forms (including all grammatical variations). Reducing these to the 1600 most frequent nouns, we then extracted all 2.5 million occurrences and linked it to important meta-information such as the date and the speaker. This data structure allows us to investigate the use of male and female

\footnotetext{
${ }^{1}$ For additional robustness tests we also include information provided by Bergmann et al. (QUELLE) as well as information we collected ourselves (e.g. on committee membership).
} 
forms across time by parties and individual MPs. Note, that our focus on female and male personal nouns does not suggest a binary objectivist view, according to which individuals neatly fit into the category of males and females. The linguistic representation of non-binary sexes has been a more recent turn in the struggle for gender-fair language that is yet to impress the official speech documentation of the Bundestag and other parliaments. ${ }^{2}$

We enrich our dictionary with different information. We categorize whether nouns refer to individuals and groups in the broader society (e. g. "citizen," "employee," "physician") or whether they are used by speakers to directly refer to or mention groups and individuals in the political realm (e. g. "colleague," "minister," "chancellor"). Based on commonly used reputation scales (Ganzeboom and Treiman 2010; Ebner and Rohrbach-Schmidt 2019) we also categorized each personal noun into a simplified prestige classification comprising higher reputation (e.g. physician, professor, employer), neutral (e. g. pensioner) and lower reputation (e. g. worker). It goes without saying that prestige and status classifications are fraught with stereotypes. Yet, it is exactly this property that enables us to shed light on the usage of "social gender" by which attitudes towards appropriate social roles for women and man (e.g. male surgeon versus female nurse) are communicated (Hellinger and Bussmann 2003: 11).

\section{Results}

The dictionary-based word extraction of 1,600 individual personal nouns yields 2.5 million lemmas of which are 2.14 million male and 353,972 female forms. Around 54 per cent of the matches refer to the political realm, 46 per cent to subjects in the broader society. ${ }^{3}$

Figure 1 plots information on the numerical (share of female MPs and ministers) and linguistic representation of women. The latter highlights that there are important differences between both groups of nouns. Nouns in the political realm experience a steeper increase of gender-fair language than nouns referring to the broader society. The curves for the share of female MPs and female members of government offer a plausible explanation for this pattern. The more women hold offices the more are female address forms used to appropriately refer to them.

This relationship between numerical presence and address forms is somewhat mechanical and less interesting in exploring party-political and sociological covariates of gender-fair language use. We will therefore concentrate on the personal nouns referring to the broader society in our multivariate analyses. Figure 1 shows that the progress in this group of nouns has been more modest. Potentially, reference to consumers or pensioners is more abstract than specific address forms and invites the use of male generics. Moreover, using feminine forms for more abstract plural nouns (e. g. demonstrators, tax payers) is not a priority for all adherents of gender-fair language.

\footnotetext{
${ }^{2}$ It has been only in June 2021 that the Bundestag administration accepts the usage of the gender-asterics (e.g. "Politiker*innen") as a marker for the inclusion of non-binary people.

${ }^{3}$ The high number of different nouns results from the fact that German is notorious for its compound words. Hence, there are not only pensioners (Rentner) but also people on a disability pension (Erwerbsminderungsrentner) or people on a workplace pension (Betriebsrentner).
} 


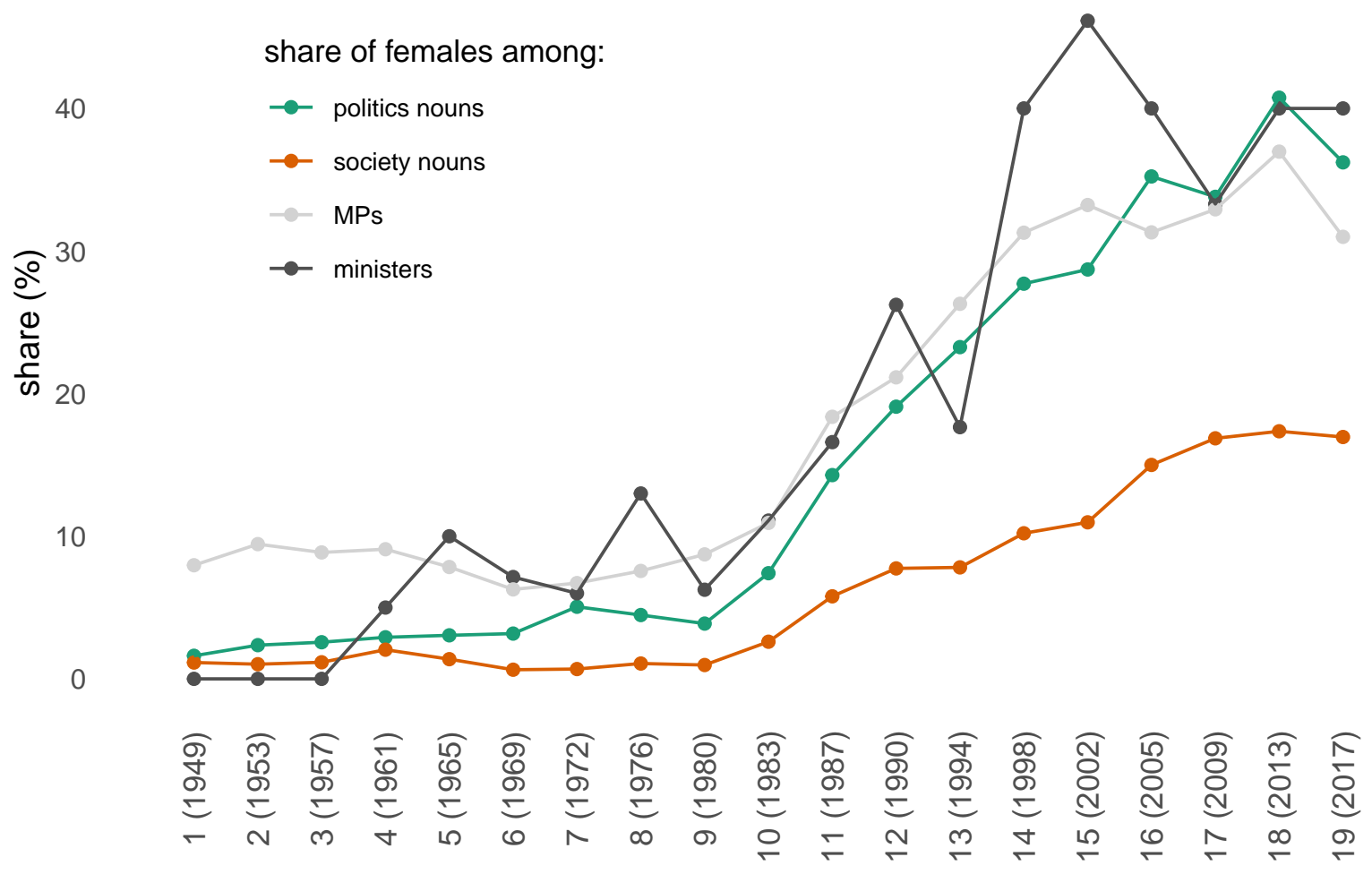

Figure 1: Share of female MPs and share of female nouns with referents in politics and society

The previous section revealed the remarkable trend in gender-fair language and underlined considerable differences between the German parties. Still, the changes in the party system tell us only so much about the factors that are responsible for the change in parliamentary speech. To disentangle the effect of several possible explanations, we run a series of fractional regression models that focus on individual level covariates. The dependent variable in our models is the share of female nouns with referents in society based on the speeches of a single MP during a legislative term. The analysis is based on 10,514 observations that represent altogether 4,156 MPs. 


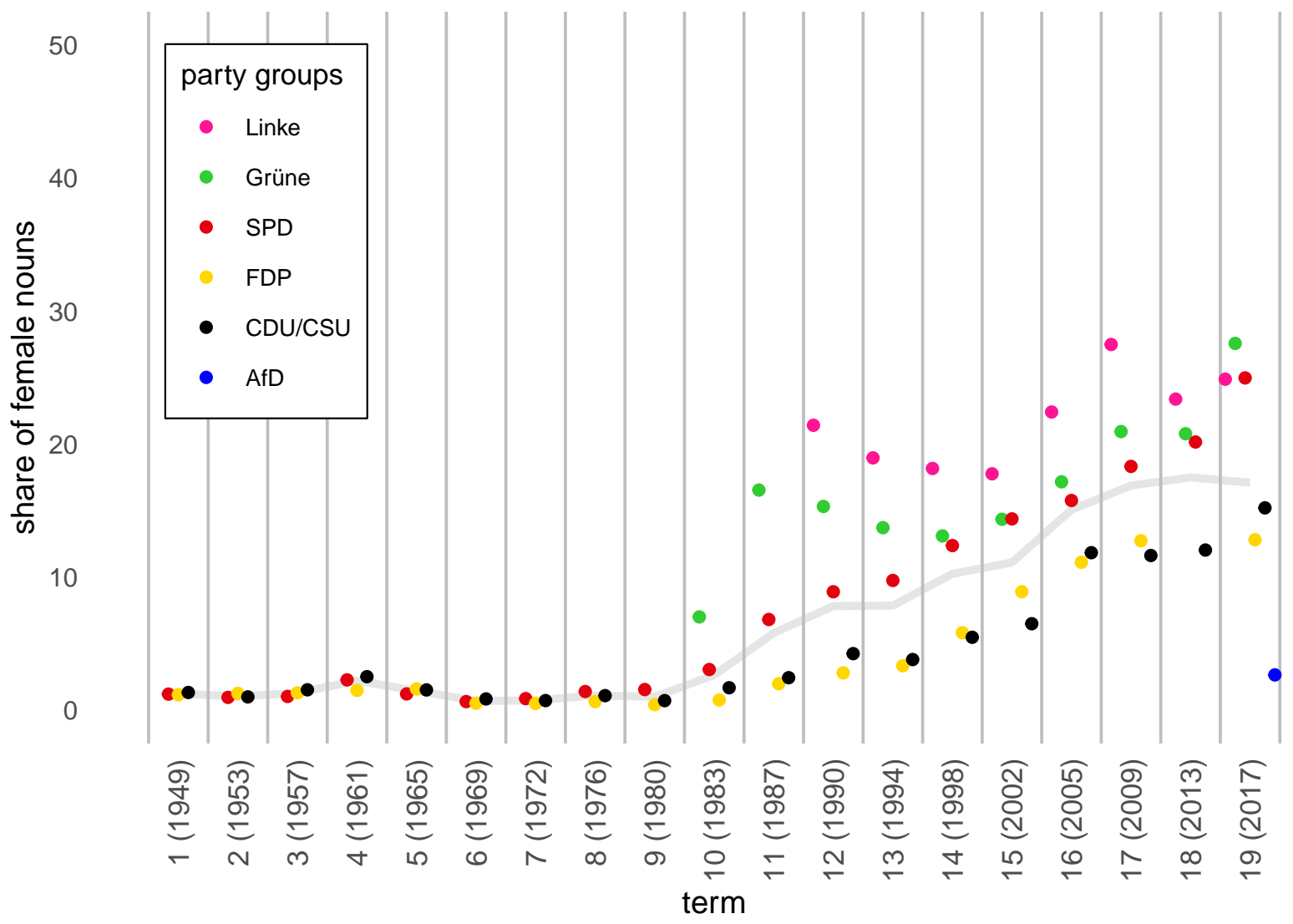

Figure 2: The use of gender-fair language by different parties

Our first regression model focuses on those who are likely responsible for the increase in gender-fair language: female MPs, whose share grew significantly in the 1980s and the 1990s. The question being whether it was their speeches or a general value change that are responsible for the changing language that we see in the aggregate. The regression model focuses on a possible interaction between MPs' gender and the legislative term. It also includes a variable that reflects the MP's day of birth, as language use will also reflect their socialization. Younger generations are expected to use more gender-fair language. Also, the regression model includes binary measures that identify individual party groups to capture possible differences in values and norms.

Figure 3 displays the predicted share of female nouns for MPs of both gender in legislative terms (95\% confidence intervals). It shows that female MPs use a more gender-fair language consistently across our period of investigation. ${ }^{4}$ This is also true for the 1950s and 1960s, where the small group of female MPs gave speeches that were quite different in that respect. From 1983 onwards, we observe a steady increase in the share of female nouns for male MPs. By contrast, for female MPs there is an initially rapid increase, within two terms the share jumped from about 2.5 per cent (1980-1983) to nearly 13 per cent (1987-1990). Since then, it has dropped slightly before it increased again recently, all of this while male MPs were closing the gap. Put differently, what we observe at the aggregate level coincides with an increasing share of female MPs whose speeches differed dramatically - particularly in the 1980s and 1990s - from the speeches given by their male colleagues.

\footnotetext{
${ }^{4}$ The differences in language is unlikely to be caused by possible differences in interests and responsibilities. For a sub-set of six legislative terms (1998-2021) we are able to control for membership in committees, as well as positions in parliament (party group leadership, spokespersons, committee chair, presidium) and government (cabinet).
} 


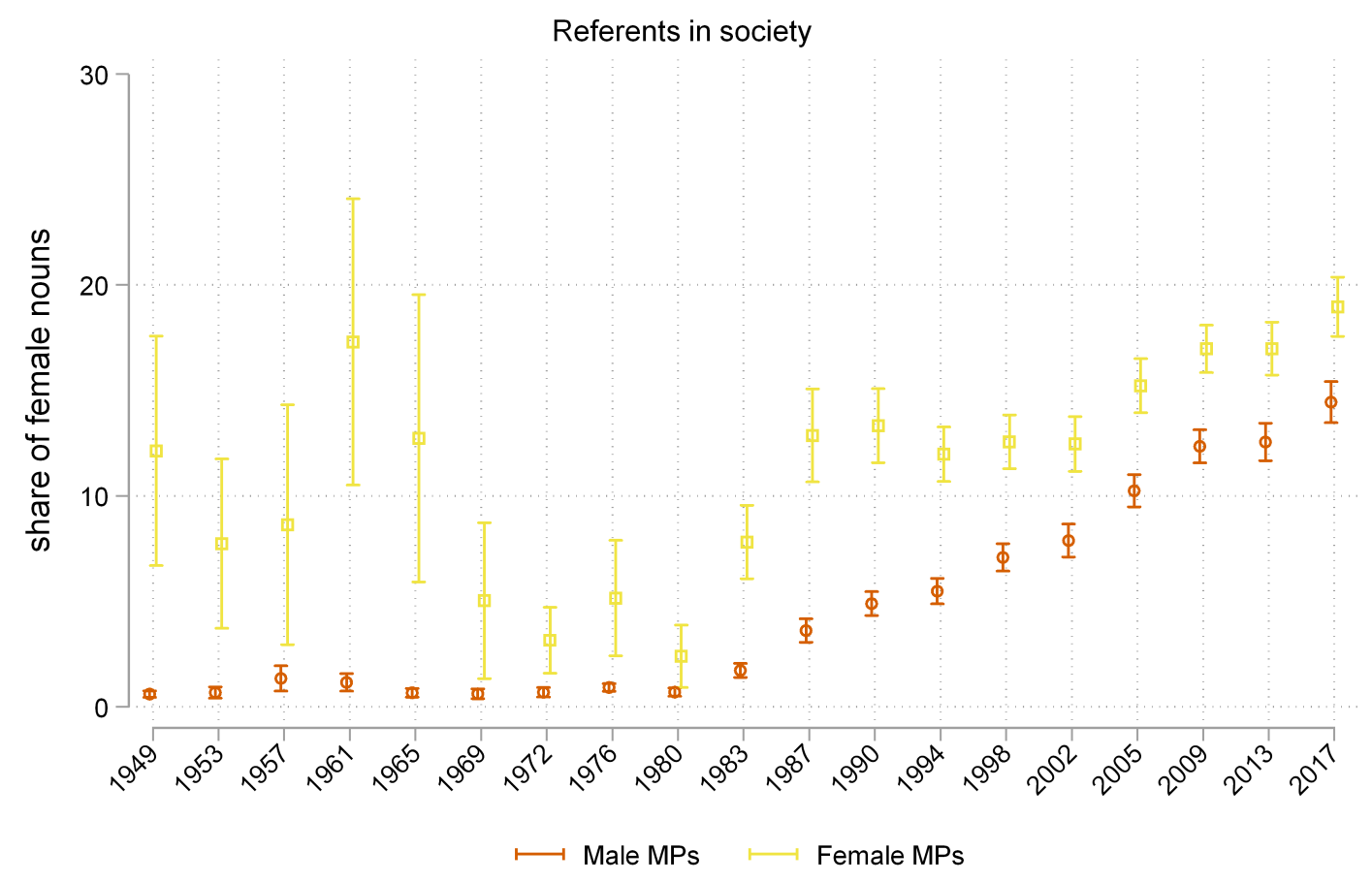

Figure 3: The use of gender-fair language by female and male MPs

Another possible driving force behind the transformation could be the addition of new generations of MPs who bring new perspectives into the Bundestag and can be the embodiment of social change. We test this argument by supplementing our analysis with a second moderator. The second regression model includes a dummy variable for freshmen MPs and an interaction between this variable, gender, and the legislative term. Figure 4 provides predictions based on the regression and focuses on those terms where we observe the most substantial changes in language use. It captures the different trends for male MPs and female MPs that we already discussed. Strikingly, there are no significant differences between freshmen MPs and incumbents. This is not only true for both groups of MPs, it also holds for the 1980s. If there was a value change, incumbent MPs internalized it in about the same way as freshman MPs. 


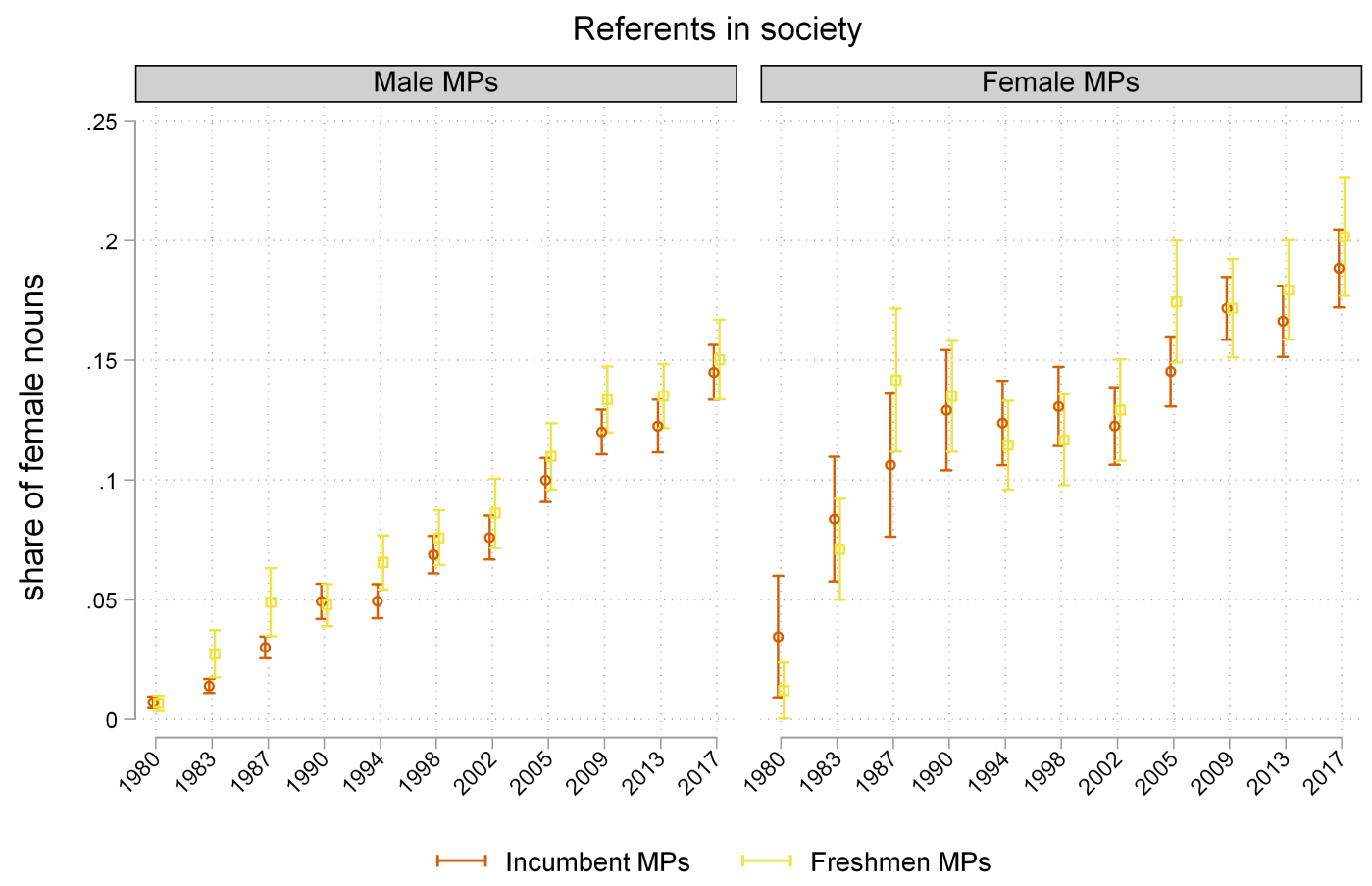

Figure 4: The use of gender-fair language by incumbent and freshmen MPs

\section{Conclusion}

Our paper sheds light on the evolution of gender-fair language in the German Bundestag since 1949. Using a novel high quality corpus we took advantage of German as a "gender language" and extracted male and female forms of the 1600 most common personal nouns. Based on 2.5 million occurrences we show that gender-inclusive language has been virtually non-existent before the Greens entered the Bundestag in 1983. The results indicate more generally that party-political factors are an important driving force of language evoluation. Next to the Greens, Left party and Social Democrats show a greater tendency than the bourgeois FDP and conservative CDU/CSU to use gender-inclusive forms. The right-wing populist AfD, however, is characterized by a exceptionally low level of gender-inclusive language.

On the individual level we identify the gender of the speaker as important factor. Language change is predominantly brought by female MPs that use female forms more often than their male colleagues regardless of party affiliation and time period. Interestingly, generational replacement has no important effect. Rather, with some lag cohorts of MPs adapt to changing language norms and habits. Our paper provided new insights into gender-inclusive language use, that forms an important part of more general debates on gender equality and value-based cleavages.

\section{References}

Bäck, Hanna, and Marc Debus. 2018. "When Do Women Speak? A Comparative Analysis of the Role of Gender in Legislative Debates" 67 (3): 576-96. https://doi.org/10.1177/0032321718789358.

Bäck, Hanna, Marc Debus, and Jorge Fernandes, eds. 2021. The Politics of Legislative Debate. Oxford: Oxford University Press. 
Bird, Karen. 2005. "Gendering Parliamentary Questions." The British Journal of Politics and International Relations 7 (3): 353-70. https://doi.org/10.1111/j.1467-856X.2005.00196.x.

Blankenship, Jane, and Deborah C. Robson. 1995. "A 'Feminine Style'; in Women's Political Discourse: An Exploratory Essay." Communication Quarterly 43 (3): 353-66. https://doi.org/10.1080/01463379509369 982.

Blätte, Andreas. 2020a. "GermaParl. Download and Augment the Corpus of Plenary Protocols of the German Bundestag."

_. 2020b. "polmineR: Verbs and Nouns for Corpus Analysis." Zenodo. https://doi.org/10.5281/zenodo.4 042093.

Blätte, Andreas, Jochen Müller, and Christian Stecker. 2021. "Germany. Parliamentary Debates Directed by Strong Party Groups." In The Politics of Legislative Debate, edited by Hanna Bäck, Marc Debus, and Jorge Fernandes. Oxford: Oxford University Press.

Boroditsky, Lera. 2009. "How Does Our Language Shape the Way We Think?" In What's Next?, edited by Max Brockman, 116-29. New York: Vintage Books.

Bratton, Kathleen A., and Leonard P. Ray. 2002. "Descriptive Representation, Policy Outcomes, and Municipal Day-Care Coverage in Norway." American Journal of Political Science 46 (2): 428-37. https://doi.org/10.2307/3088386.

Bußmann, Hadumod, and Marlis Hellinger. 2003. "Engendering Female Visibility in German." In Gender Across Languages, edited by Marlis Hellinger, 141-74. Impact. Amsterdam: Benjamins.

Cameron, Deborah, ed. 2003. The Feminist Critique of Language: A Reader. 2. ed., reprinted. London: Routledge.

2012. On Language and Sexual Politics. Routledge. https://doi.org/10.4324/9780203715369.

Celis, Karen. 2006. "Substantive Representation of Women: The Representation of Women's Interests and the Impact of Descriptive Representation in the Belgian Parliament (1900-1979)." Journal of Women, Politics \& Policy 28 (2): 85-114. https://doi.org/10.1300/J501v28n02\%7B/textunderscore\%20\%7D04.

Dietrich, Bryce J.., Matthes Hayes, and Diana Z. O'Brien. 2019. "Pitch Perfect: Vocal Pitch and the Emotional Intensity of Congressional Speech." American Political Science Review 113 (4): 941-62. https://doi.org/10.1017/S0003055419000467.

Ebner, Christian, and Daniela Rohrbach-Schmidt. 2019. Berufliches Ansehen in Deutschland für Die Klassifikation Der Berufe 2010: Beschreibung Der Methodischen Vorgehensweise, Erste Deskriptive Ergebnisse Und güte Der Messung. Version 1.0. BIBB-Preprint. Bonn: Bundesinstitut für Berufsbildung; Bundesinstitut für Berufsbildung.

Eder, Christina, Jessica Fortin-Rittberger, and Corinna Kroeber. 2016. "The Higher the Fewer? Patterns of Female Representation Across Levels of Government in Germany." Parliamentary Affairs 69 (2): 366-86. https://doi.org/10.1093/pa/gsv021.

Ganzeboom, Harry B. G., and Donald J. Treiman. 2010. "International Stratification and Mobility File: Conversion Tools." Amsterdam. http://www.harryganzeboom.nl/ismf/index.htm.

Goebel, Sascha, and Simon Munzert. 2020. "legislatoR: Interface to the Comparative Legislators Database. R Package Version 1.0." https://CRAN.R-project.org/package=legislatoR.

Gygax, Pascal Mark, Daniel Elmiger, Sandrine Zufferey, Alan Garnham, Sabine Sczesny, Lisa von Stockhausen, Friederike Braun, and Jane Oakhill. 2019. "A Language Index of Grammatical Gender Dimensions to Study the Impact of Grammatical Gender on the Way We Perceive Women and Men." Frontiers in Psychology 10: 1604. https://doi.org/10.3389/fpsyg.2019.01604.

Hargrave, Lotte, and Tone Langengen. 2020. "The Gendered Debate: Do Men and Women Communicate Differently in the House of Commons?" Politics \& Gender, 1-27. https://doi.org/10.1017/S1743923X200 
00100

Hellinger, Marlis. 2001. "English - Gender in a Global Language." In Gender Across Languages, edited by Marlis Hellinger, Hadumod Bussmann, and Heiko Motschenbacher, 105-13. Impact, Studies in Language and Society. Amsterdam; Philadelphia: J. Benjamins.

Hellinger, Marlis, and Hadumod Bussmann. 2003. "The Linguistic Representation of Women and Men." In Gender Across Languages, edited by Marlis Hellinger, 1-25. Impact. Amsterdam: Benjamins.

Hellinger, Marlis, Hadumod Bussmann, and Heiko Motschenbacher, eds. 2015. Gender Across Languages: The Linguistic Representation of Women and Men. Vol. v. 9-<11, $36>$. Impact, Studies in Language and Society. Amsterdam; Philadelphia: J. Benjamins.

Inglehart, Ronald, and Pippa Norris. 2005. Rising Tide: Gender Equality and Cultural Change Around the World. Reprinted. Cambridge: Cambridge Univ. Press. http://www.loc.gov/catdir/samples/cam033/20 02031077.html.

Kinsky, Lucy, Marius Sältzer, and Stefanie Walter. 2021. "Beyond Women's Issues - Substantive Representation and Gendered Language Use in Legislative Speech." Manuscript.

Kriesi, Hanspeter. 2010. "Restructuration of Partisan Politics and the Emergence of a New Cleavage Based on Values." West European Politics 33 (3): 673-85. https://doi.org/10.1080/01402381003654726.

Lakoff, Robin. 1973. "Language and Woman's Place." Language in Society 2 (1): 45-79. https://doi.org/10.1 $017 / \mathrm{S} 0047404500000051$.

Lovenduski, Joni. 2005. Feminizing Politics. Cambridge: Polity.

Lowndes, Vivien. 2020. "How Are Political Institutions Gendered?" Political Studies 68 (3): 543-64. https://doi.org/10.1177/0032321719867667.

Mansbridge, Jane. 1999. "Should Blacks Represent Blacks and Women Represent Women? A Contingent Yes." The Journal of Politics 61 (3): 628-57. https://doi.org/10.2307/2647821.

Norris, Pippa. 2004. Electoral Engineering: Voting Rules and Political Behavior. Cambridge: Cambridge University Press. https://doi.org/10.1017/CBO9780511790980.

Phillips, Anne. 2003. The Politics of Presence: The Political Representation of Gender, Ethnicity, and Race. Reprinted. Oxford Political Theory. Oxford: Oxford Univ. Press.

Prewitt-Freilino, Jennifer L., T. Andrew Caswell, and Emmi K. Laakso. 2012. "The Gendering of Language: A Comparison of Gender Equality in Countries with Gendered, Natural Gender, and Genderless Languages." Sex Roles 66 (3-4): 268-81. https://doi.org/10.1007/s11199-011-0083-5.

Proksch, Sven-Oliver, and Jonathan B. Slapin. 2012. "Institutional Foundations of Legislative Speech." American Journal of Political Science 56 (3): 520-37. https://doi.org/10.1111/j.1540-5907.2011.00565.x.

Reynolds, David J., Alan Garnham, and Jane Oakhill. 2006. "Evidence of Immediate Activation of Gender Information from a Social Role Name." Quarterly Journal of Experimental Psychology (2006) 59 (5): 886-903. https://doi.org/10.1080/02724980543000088.

Sczesny, Sabine, Magda Formanowicz, and Franziska Moser. 2016. "Can Gender-Fair Language Reduce Gender Stereotyping and Discrimination?" Frontiers in Psychology 7: 25. https://doi.org/10.3389/fpsyg. 2016.00025.

Stahlberg, Dagmar, Friederike Braun, Lisa Irmen, and Sabine Sczesny. 2007. "Representation of the Sexes in Language." In Social Communication, edited by Klaus Fiedler, 163-87. Frontiers of Social Psychology. New York: Psychology Press.

Thomas, Sue. 1994. How Women Legislate. New York: Oxford Univ. Press. http://www.loc.gov/catdir/enh ancements/fy0602/93004264-d.html. 
Tresch, Anke. 2008. "Politicians in the Media: Determinants of Legislators' Presence and Prominence in Swiss Newspapers." The International Journal of Press/Politics 14 (1): 67-90. https://doi.org/10.1177/ 1940161208323266.

Twenge, Jean M., W. Keith Campbell, and Brittany Gentile. 2012. "Male and Female Pronoun Use in u.s. Books Reflects Women's Status, 1900-2008." Sex Roles 67 (9-10): 488-93. https://doi.org/10.1007/s11199012-0194-7.

Valentim, Vicente, and Tobias Widmann. 2021. "Does Radical-Right Success Make the Political Debate More Negative? Evidence from Emotional Rhetoric in German State Parliaments." Political Behavior. https://doi.org/10.1007/s11109-021-09697-8.

Wängnerud, Lena. 2009. "Women in Parliaments: Descriptive and Substantive Representation." Annual Review of Political Science 12 (1): 51-69. https://doi.org/10.1146/annurev.polisci.11.053106.123839.

Wickham, Hadley, Mara Averick, Jennifer Bryan, Winston Chang, Lucy McGowan, Romain François, Garrett Grolemund, et al. 2019. "Welcome to the Tidyverse." Journal of Open Source Software 4 (43): 1686. https://doi.org/10.21105/joss.01686.

Young, Iris Marion. 2010. Inclusion and Democracy. Oxford Political Theory. Oxford: Oxford University Press. 


\title{
Appendix: The evolution of gender-inclusive language. Evidence from the German Bundestag, 1949-2021
}

\author{
Christian Stecker (Technical University of Darmstadt) \\ Jochen Müller (Humboldt-Universität zu Berlin) \\ Andreas Blätte (University of Duisburg-Essen) \\ Christoph Leonhardt (University of Duisburg-Essen)
}

14.07.2021

\section{Contents}

GermaParl - a corpus of legislative debates in the German Bundestag, 1949-2020 1

$\begin{array}{ll}\text { Extracting male and female personal nouns with a dictionary } & 1\end{array}$

$\begin{array}{ll}\text { References } & 4\end{array}$

\section{GermaParl - a corpus of legislative debates in the German Bun- destag, 1949-2020}

GermaParl is a high-quality corpus containing all speeches of the German Bundestag. It is linguistically annotated and indexed based on the Open Corpus Workbench (CWB).

\section{Extracting male and female personal nouns with a dictionary}

We apply a dictionary to the GermaParl-corpus that extracts male and female personal nouns. As a gender language, each noun in German carries a gender marking (or grammatical gender): male, female or neuter (Stahlberg et al. 2007: 164-166). In German, female personal nouns are almost exclusively created by derivations from generic masculines (Bußmann and Hellinger 2003: 153). By adding the suffix "in" (singular) or "innen" (plural), generic masculine forms are turned into female nouns.

This structural feature of the German language makes the extraction of male and female semantically symmetric pairs a straightforward task. We devised a respective dictionary for all personal nouns ever uttered

Table 1: Examples of male and female personal nouns

\begin{tabular}{lll}
\hline English noun & male form (singular/plural) & female form (singular/plural) \\
\hline politician(s) & der Politiker/die Politiker & die Politikerin/die Politikerinnen \\
citizen(s) & der Bürger/die Bürger & die Bürgerin/die Bürgerinnen \\
athlete(s) & der Sportler/die Sportler & die Sportlerin/die Sportlerinnen \\
teacher(s) & der Lehrer/die Lehrer & die Lehrerin/die Lehrerinnen \\
\hline
\end{tabular}


in the debates of the German Bundestag. For the 1600 most frequent nouns we constructed regular expressions to extract all female and male personal nouns covering all grammatical variations, most importantly singular and plural forms.

Applying our dictionary to the GermaParl-corpus yields 353972 female personal nouns and 2140135 male personal nouns. Table 2 presents information for the 30 most frequent nouns. It includes the regular expressions (including plural forms and declensions) deployed for the extraction and the number of matches of female and male forms. Moreover, the share of matches on the total number of harvested nouns is given as well as the ratio of female forms for each noun. It is also indicated whether a noun refers to subjects in the political realm (e.g. "colleague" or "minister") or to the wider society (e.g. "citizen").

Table 2: Dictionary (extract) of male and female personal singular and plural nouns

\begin{tabular}{|c|c|c|c|c|c|c|c|c|}
\hline english & male regex & female regex & category & female (n) & male (n) & words & share & female_ratio \\
\hline colleague & Kollege(n)? & Kollegin(nen)? & politics & 140288 & 420086 & 560374 & 22.47 & 25.03 \\
\hline president & Präsident(en)? & Präsidentin(nen)? & politics & 57723 & 146472 & 204195 & 8.19 & 28.27 \\
\hline minister & $\operatorname{Minister}(\mathrm{n} \mid \mathrm{s}) ?$ & Ministerin(nen)? & politics & 17734 & 74324 & 92058 & 3.69 & 19.26 \\
\hline citizen & Bürger $(\mathrm{n} \mid \mathrm{s}) ?$ & Bürgerin(nen)? & society & 20095 & 70685 & 90780 & 3.64 & 22.14 \\
\hline state secretary & Staatssekretär(s|e|en)? & Staatssekretärin(nen)? & politics & 7245 & 68853 & 76098 & 3.05 & 9.52 \\
\hline chancellor & Bundeskanzler $(\mathrm{n} \mid \mathrm{s}) ?$ & Bundeskanzlerin(nen)? & politics & 7820 & 60634 & 68454 & 2.74 & 11.42 \\
\hline employee & Arbeitnehmer $(\mathrm{n} \mid \mathrm{s}) ?$ & Arbeitnehmerin(nen)? & society & 6584 & 41326 & 47910 & 1.92 & 13.74 \\
\hline soldier & Soldat(en)? & Soldatin(nen)? & society & 6893 & 35579 & 42472 & 1.70 & 16.23 \\
\hline federal minister & Bundesminister $(\mathrm{n} \mid \mathrm{s}) ?$ & Bundesministerin(nen)? & politics & 2143 & 33994 & 36137 & 1.45 & 5.93 \\
\hline representative & Vertreter $(\mathrm{n} \mid \mathrm{s}) ?$ & Vertreterin(nen)? & politics & 1405 & 25670 & 27075 & 1.09 & 5.19 \\
\hline consumer & Verbraucher $(\mathrm{n} \mid \mathrm{s}) ?$ & Verbraucherin(nen)? & society & 4356 & 20761 & 25117 & 1.01 & 17.34 \\
\hline employee & Mitarbeiter $(\mathrm{n} \mid \mathrm{s}) ?$ & Mitarbeiterin(nen)? & society & 4729 & 20071 & 24800 & 0.99 & 19.07 \\
\hline social democrat & Sozialdemokrat(en)? & Sozialdemokratin(nen)? & politics & 986 & 23510 & 24496 & 0.98 & 4.03 \\
\hline partner & $\operatorname{Partner}(\mathrm{n} \mid \mathrm{s}) ?$ & Partnerin(nen)? & society & 326 & 22371 & 22697 & 0.91 & 1.44 \\
\hline friend & Freund $(\mathrm{en}|\mathrm{s}| \mathrm{es} \mid \mathrm{e}) ?$ & Freundin(nen)? & society & 616 & 21916 & 22532 & 0.90 & 2.73 \\
\hline public servant & $\operatorname{Beamte}(\mathrm{n} \mid \mathrm{r}) ?$ & Beamtin(nen)? & society & 1162 & 20913 & 22075 & 0.89 & 5.26 \\
\hline finance minister & Finanzminister $(\mathrm{s} \mid \mathrm{n}) ?$ & Finanzministerin(nen)? & politics & 106 & 19395 & 19501 & 0.78 & 0.54 \\
\hline doctor & $\operatorname{Arzt}(\mathrm{es}) ? \mid \ddot{A r z t e}(\mathrm{n}) ?$ & Ärztin(nen)? & society & 1626 & 16317 & 17943 & 0.72 & 9.06 \\
\hline professor & Professor(s|en)? & Professorin(nen)? & society & 213 & 17255 & 17468 & 0.70 & 1.22 \\
\hline Bavarian & Bayer $(\mathrm{n}) ?$ & Bayerin(nen)? & society & 23 & 17408 & 17431 & 0.70 & 0.13 \\
\hline pensioner & Rentner(n|s)? & Rentnerin(nen)? & society & 2896 & 14047 & 16943 & 0.68 & 17.09 \\
\hline employer & Arbeitgeber $(\mathrm{n} \mid \mathrm{s}) ?$ & Arbeitgeberin(nen)? & society & 239 & 16383 & 16622 & 0.67 & 1.44 \\
\hline prime minister & Ministerpräsident(en)? & Ministerpräsidentin(nen)? & politics & 373 & 15589 & 15962 & 0.64 & 2.34 \\
\hline lawmaker & Gesetzgeber $(\mathrm{s} \mid \mathrm{n}) ?$ & Gesetzgeberin(nen)? & politics & 17 & 15300 & 15317 & 0.61 & 0.11 \\
\hline politician & Politiker(n|s)? & Politikerin(nen)? & politics & 1022 & 13802 & 14824 & 0.59 & 6.89 \\
\hline foreign minister & Außenminister $(\mathrm{n} \mid \mathrm{s}) ?$ & Außenministerin(nen)? & politics & 138 & 14331 & 14469 & 0.58 & 0.95 \\
\hline farmer & $\operatorname{Bauer}(\mathrm{s} \mid \mathrm{n}) ?$ & Bäuerin(nen)? & society & 1481 & 11579 & 13060 & 0.52 & 11.34 \\
\hline entrepreneur & Unternehmer $(\mathrm{n} \mid \mathrm{s}) ?$ & Unternehmerin(nen)? & society & 538 & 12258 & 12796 & 0.51 & 4.20 \\
\hline patient & Patient(en)? & Patientin(nen)? & society & 2232 & 10328 & 12560 & 0.50 & 17.77 \\
\hline democrat & Demokrat(en)? & Demokratin(nen)? & society & 251 & 11979 & 12230 & 0.49 & 2.05 \\
\hline
\end{tabular}

54.60 per cent of all results consist of nouns referring to the political realm. This group is strongly dominated by adress forms that are typical for direct communiation a in parliament. MPs usually start their speech with adressing the Speaker of the Bundestag ("Bundestagspräsident") and also their fellow MPs as "colleague." In speeches reference to members of government as "minister" is also common. In adressing a specific person it is the norm to use a gender-specific noun. The category of nouns referring to persons outside politics is less concentrated; "citizen," "employee," and "soldier" are the most frequent occurrences. 
noun

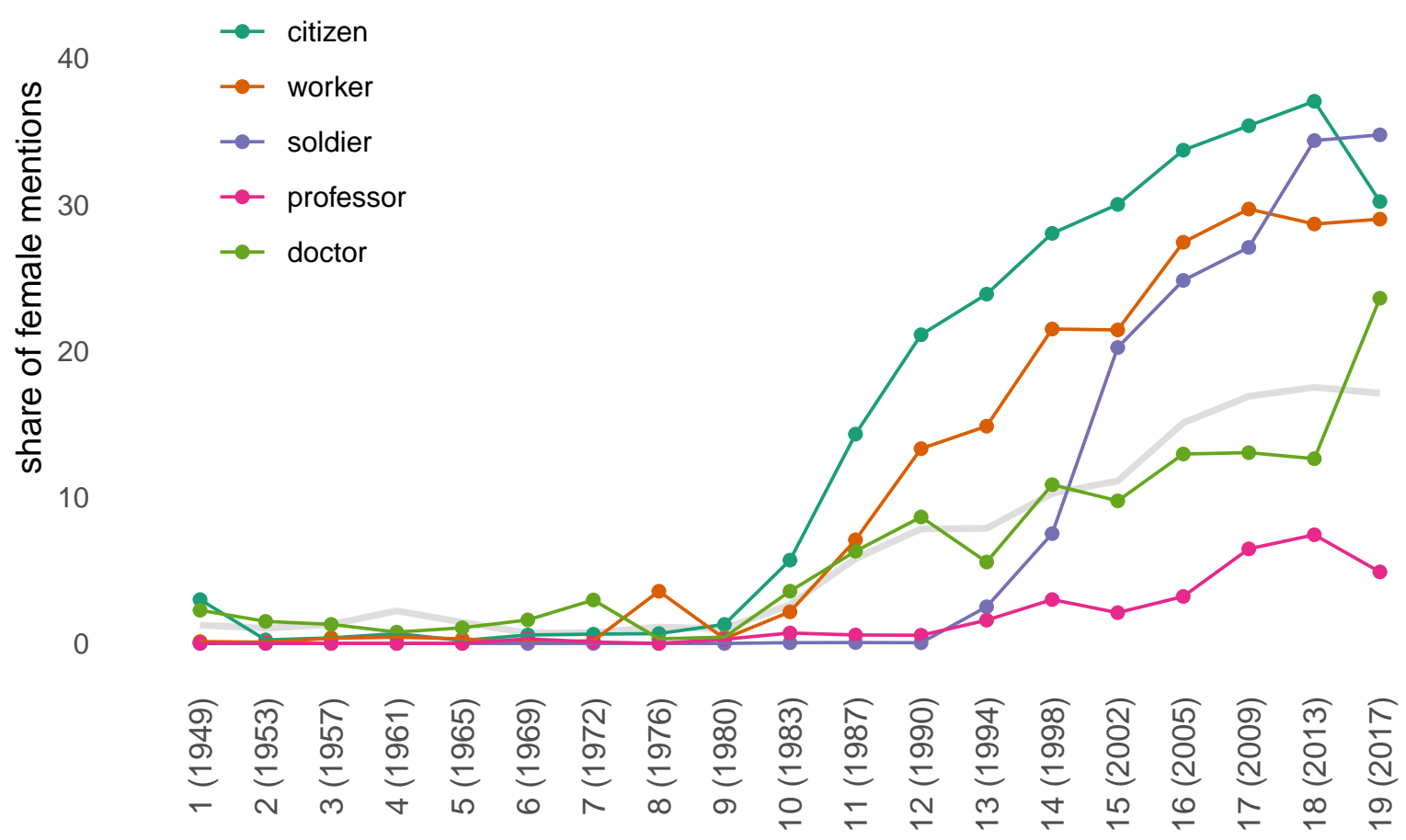




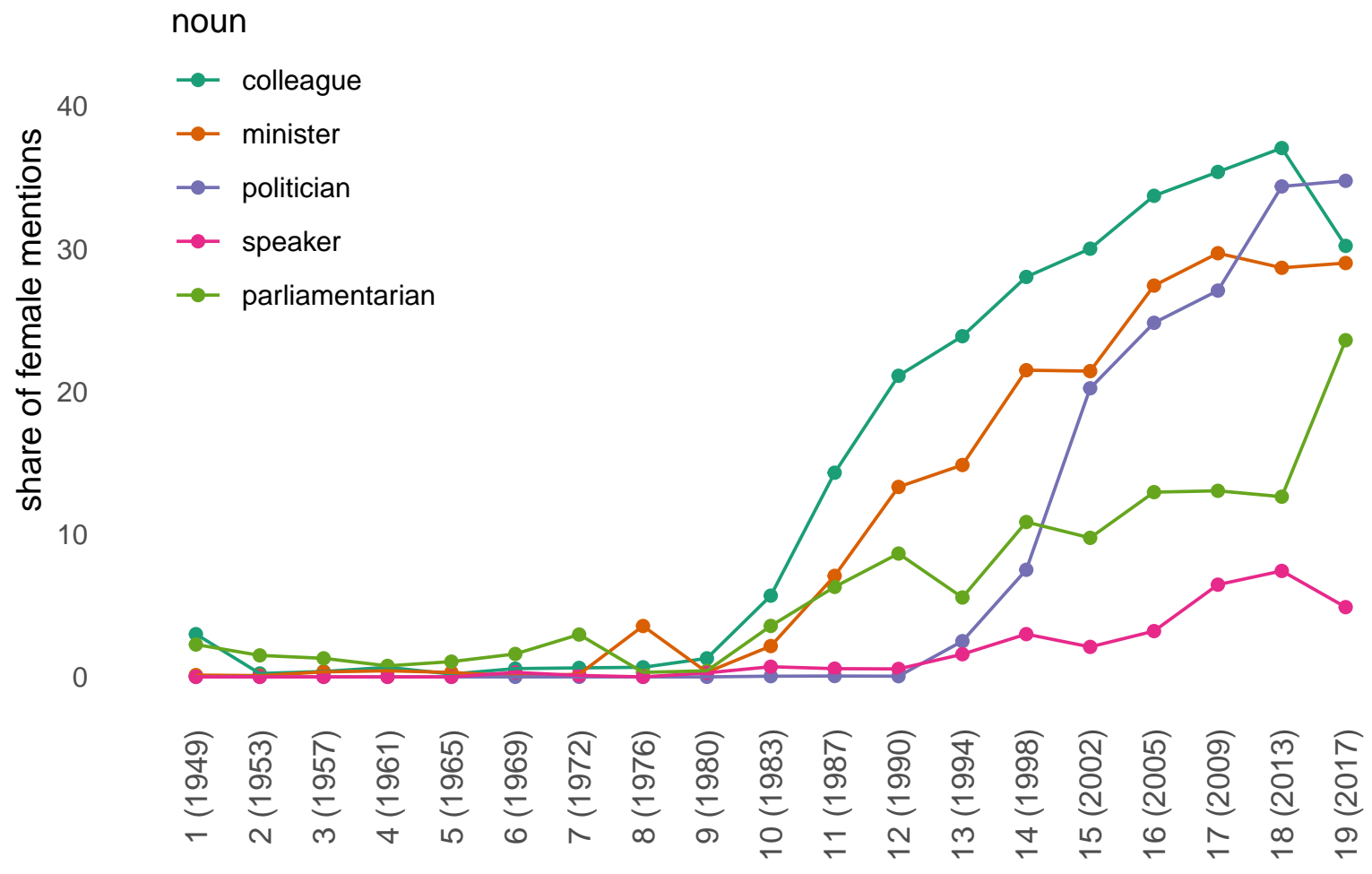

\section{References}

Bußmann, Hadumod, and Marlis Hellinger. 2003. "Engendering Female Visibility in German." In Gender Across Languages, edited by Marlis Hellinger, 141-74. Impact. Amsterdam: Benjamins.

Stahlberg, Dagmar, Friederike Braun, Lisa Irmen, and Sabine Sczesny. 2007. "Representation of the Sexes in Language." In Social Communication, edited by Klaus Fiedler, 163-87. Frontiers of Social Psychology. New York: Psychology Press. 